Reseñas

\title{
Juan Florit. Caudillo de los veleros. Introducción, recopilación, bibliografía y notas de Andrés Florit Cento
}

Santiago: Editorial Cuarto Propio, 2006, 485 pp.

\author{
Santiago Aránguiz Pinto \\ Universidad D iego Portales. Santiago, Chile \\ santiago.aranguiz@udp.cl
}

- SPECIAL interés ha generado durante los últimos años la realización de es-

- tudios y monografías biográficas sobre algunos intelectuales, escritores y poetas nacionales que, hasta el momento, habían permanecido ocultos para el público en general y que, ahora, gracias a la labor emprendida por entusiastas investigadores, cada vez adquieren un relieve mayor, estimulando de esta manera la puesta en práctica de investigaciones literarias e historiográficas ligadas a los diferentes campos del arte y la cultura en general. Estas están apoyadas en rigurosas metodologías de trabajo y en la acuciosidad de la búsqueda de fuentes en diarios, revistas y archivos personales, además del cada vez más creciente sustento teórico y una interesante discusión epistemológica del quehacer crítico e intelectual, lo que ha generado que nos encontremos actualmente en una excel ente situación de los estudios literarios en el país abordados desde la problemática de la historia cultural.

Este estímulo hacia la elaboración de libros recopilatorios y críticos, como el realizado por el periodista Andrés Florit C ento (1982, licenciado en la Universidad de Chile), constituye la demostración del enorme interés que ha generado, incluso entre los estudiantes universitarios, la investigación histórica y literaria, quemuchas vecesseentrecruza y retroalimenta, posibilitan do la confluencia de disciplinas que mucho tienen que aportar entre ellas, fomentando a la vez la divulgación del acervo cultural chileno que, por lo demás, clama por una mayor difusión en los colegios y en las universidades. Estas últimas, a través de sus sellos editoriales, se han percatado de esta necesidad, y se encuentran en una fase altamente auspiciosa, lo que augura un interesante panorama editorial, fomentando de esta manera la investigación académica entre jóvenes investigadores.

D entro de este contexto de revalorización de la cultura nacional a través de 
la publicación de libros que compilan y estudian la obra dispersa e inédita de al gunos narradores chilenos que se encuentran en la categoría de "mitos", apoyados en logrados estudios histórico-literarios o en la confección de prólogos sugerentes y estimulantes, se comprende la labor que algunos historiadores y estudiosos han realizado para rescatar la figura de poetas como Jorge $C$ áceres, Teófilo Cid, Romeo M urga o Luis O yarzún. No son losúnicos, por cierto, pero dan cuenta del creciente entusiasmo de al gunos investigadores por adentrarse en las distintas expresiones artísticas con el objetivo de ensanchar los márgenes de la reducida cultura "oficial" que sólo se preocupa de difundir a Gabriela M istral o Pablo N eruda, como si no existiesen otro tipo de creadores que tuvieran relevancia en su momento, que fueron capaces de generar una propuesta narrativa sólida, coherente, original y permanente en el tiempo, pese a que no tuvieran la figuración de aquéllos, quienes, lamentablemente, actuaron como una especie de paraguas que entorpeció la difusión de otros escritores que se vieron opacados por la estela magnética que ejercieron ambos poetas.

Es el caso deJuan Florit (1900-1981) representa, sin duda, el de un absoluto desconocido para el ambienteliterario chileno, como así también, incluso, para los académicos y profesores de literatura, quienes, por diversos motivos, han ignorado abiertamente este tipo de poetas, lo que acrecienta por lo tanto la escasa difusión que tienen creadores como G ustavo 0 ssorio y C arlos de Rokha, entre otros, que en la actualidad esperan, al igual que Florit -aunque hoy la deuda está pagada en el caso de este último-, por alguien que se preocupe de estudiar la obra y la vida de los "postergados", de aquellos escritores que se situaron en un nivel secundario en la escena literaria chilena, aunque no por ello menos interesante. La lista es larga y podríamos seguir enumerando por largo rato más, pero a lo que apuntamos es a destacar el impulso de nuevos investigadores que, con escaso apoyo económico y la adversidad con quedeben luchar en la burocracia de las bibliotecas públicas, han logrado, pese a todo, emprender trabajos de investigación sobre la literatura nacional y sus movimientos culturales y artísticos del siglo XX, acrecentando de esta manera una todavía alicaída producción intelectual que nos posicione como un país que se preocupa realmente de estudiar, analizar y difundir la obra de los escritores nacionales que aún permanecen en el anonimato absoluto. Afortunadamente, el Consejo $\mathrm{Na}$ cional del Libro y la Lectura financia este tipo de proyectos, provocando de este forma un incentivo para todos quienes realizan estos estudios, aunque todavía el apoyo es escaso y se requiere de más ayuda económica, tanto para el trabajo investigativo propiamente tal como para la publicación del material.

Pues bien, el libro Juan Florit. Caudillo de los veleros, de reciente publicación a través de la editorial Cuarto Propio, cuya introducción, recopilación, bibliografía y notas estuvo a cargo del nieto del poeta español-chileno, se inserta ple- 
namente dentro del contexto ya aludido, y es además una clara demostración de la proliferación de trabajos intelectual es que se han abocado con especial cuidado en estudiar y ponderar adecuadamente la obra de determinados poetas que, a la luz de los aportes real izados por investigadores jóvenes, adquieren una condición distinta que genera una valorización mayor de sus textos, no obstante el tiempo transcurrido y la aparente escasa vigencia de susfundamentos estéticosy estilo literario.

La publicación del volumen queahora comentamos requiere de al gunas consideraciones fundamentales para situar la importancia de su edición, y de esta manera contextualizar la vida de Florit y situar la propuesta estética que se caracterizó por haber participado durante la década de 1920 con los primeros brotes vanguardistas ligados al grupo "Ariel", que editaba su propia revista y donde colaboraron Rosamel del Valley H omero Arce. M uy distinta, en cambio, será su propuesta estética durante las próximas décadas, atravesando por un acendrado lirismo, desembocando finalmente en una poesía retrospectiva, íntima, definas pulsaciones, con un toque deoriginal anacronismo y peculiar desfase temporal respecto de las turbulencias sociales y políticas de cada época, dando a entender que lo suyo no era definitivamente la poesía social de fuerte compromiso cívico; prevalece en él un tipo de escritura arraigada en la serenidad del espíritu acorde a las inquietudes estéticas de quien supo desligarse de las expresiones rupturistas para encontrar una voz propia y original, un estilo literario identificable consigo mismo, transformándolo desde un fiel entusiasta que incentivaba la publicación de creaciones vanguardistas, hacia un poeta que se situó en los márgenes del canon literario chileno, no precisamente por su propuesta transgresora (remarcada durante su juventud), sino más bien por su alejamiento del bullicio editorial ubicado en los centros gravitacional es dela cultura chilena. Florit prefirió desarrollar un trabajo literario silencioso, distanciado de capillas de poder y figuración, lo cual explica que recién a los58 años de edad haya editado su primer libro, pese a haber publicado poemas y colaboraciones en prosa desde 1917 en las revistas El Peneca y Zig-Zag.

Con todo, el libro de Andrés Florit es un aporte significativo para el estudio de la cultura nacional del siglo XX y sus expresiones literarias, especial mente en referencia a contextos y ambientes artísticos fuera de lo comúnmente establecido desde la oficialidad política o ideológica, transformándose de esta manera en una investigación histórico-literaria fundamental para ahondar en los territorios ignotos de la escena cultural chilena, mostrándonos un rostro diferente y desconocido para muchos, iluminado por hallazgos poéticos dealto vuel o y, por qué no decirlo, por la intensa vocación literaria de Florit, que se mantuvo con persistencia durante más de 60 años. 